\section{MOUNT WASHINGTON IN WINTER}

$\mathrm{BY}$ the kindness of an American friend, we have been favoured with a Boston newspaper containing an account of an important meteorological experiment which has recently been tried in America with the greatest success; we refer to the establishment of a winter observatory on the summit of Mount Washington at an elevation of something like 10,000 feet above sea-level.

Everybody knows that Mount Washington, in New Hampshire, is visited by thousands of persons in the summer months, and that its climate corresponds better with that of Labrador or Greenland than with that of New England. In the winter universal desolation reigns there; not even the proprietors of the hotels upon the summit venturing from their snug quarters below to learn what events are transpiring upon the icy cone. The aborigines declared it to be sure death if anyone climbed the mountain-since it was the sanctuary of divinities who would not suffer their abode to be scanned with impunity. Their successors first adventurously found the summit - then erected rude places for shelter, and finally constructed a carriage road and railway, so that even the most feeble persons could view the broad panorama. But these visits were confined to the warmer months, with a few rare exceptions.

Twelve years ago Profs. C. H. Hitchcock and J. H. Huntington, independently of each other, conceived the project of spending the winter upon the summit of Mount Washington, but the project did not take shape till the organisation of the Geological Survey of New Hampshire in 1868 . They found it impossible to make the necessary preparations for occupying the summit during the winter of $\mathbf{1} 868$, chiefly for want of a dwelling. Hence they sought for a less elevated summit, where a single winter's experience might prepare the way for the greater adventure. That peak was Mooselauke, nearly 5,000 feet above the ocean. The lessee, D. G. Marsh, of Warren, N.H., obligingly placed his house at the service of Prof. Huntington and his comrade, A. F. Clough, of Warren, photographer. Their three months' occupation of Mooselauke was full of adventure, and experiences were acquired of the highest importance. The scientific results were important, disclosing the knowledge of violent winds there accurately measured, and remarkable forms of frost-work never before described or photographed. Attention was called to this mountain, and a carriage road became a necessity, which was constructed in the following summer.

In the month of September, 1869 , the Mount Washington Railway Company generously tendered the use of their depôt upon the summit to this meteorological party during the winter; and the necessary supplies were immediately purchased and forwarded to the mountain. The enterprise, though of a meteorological character, has been adopted by the Geological Survey of the State, while the expense has been assumed by the State geologist, relying upon a sympathising public to provide the funds by subscription.

Congress recently appropriated funds for the establishment of a "Bureau of Telegrams and Reports for the Benefit of Commerce." After some correspondence with the efficient officer in charge of this bureau, General Myer ordered an insulated telegraph wire with suitable instruments ti be sent to the mountain, in order to facilitate the transmission of the meteorological reports, both to the public and to the office of the bureau in Washington. The wire has been laid, and the summit is now in telegraphic communication with the world. And the chief signal officer also detailed for special service upon the mountain an experienced telegrapher and meteorologist, Sergeant Theodore Smith, of the U.S. Army.

The photographers of the expedition are Mr. A. F.Clough, of Warren, and Mr. Howard A. Kimball, of Concord, N.H. The latter gentleman spent much time in providing photo- graphic material for the mountain, and in soliciting subscriptions. Their views of the peculiar phenomena of the mountain will soon be exhibited.

Thus the party consists of six persons: Prof. Hitchcock, whose office in Hanover, N.H., is connected by telegraph with the summit; Prof. Huntington and $\mathrm{Mr}$. Nelson, observers; Messrs. Clough and Kimball, photographers; and Sergeant Smith, telegrapher and observer. All of them are not upon the mountain at the same time. They relieve each other to a considerable extent in the work, and the public will be kept informed of their whereabouts.

From the dépôt of the Mount Washington Railway in summer, the ascent on foot, if a person is accustomed to walking, is comparatively easy. Although the ties are three feet apart, and there is a rise of a foot in three part of the way, yet a person with muscles strong from exercise, can walk to the very summit of the mountain without sitting down to rest. But suppose it is winter. The snow has accumulated to a considerable depths even in the ties, but then it is no great hindrance should it, however, be attempted a second time, you will find that the snow that was compressed beneath the feet has changed to ice, and the oval forms give a still less secure footing; if it is thawing, and the ice is almost ready to slip off as you tread upon it, every one will see that upon a trestle thirty feet high walking is somewhat dangerous, and to walk down is a feat from which even a most expert acrobat would shrink. If at the dépôt we take snow shoes, we can walk with comparative ease half way up, and then the snow is so compact that they are no longer needed, and as there are few irregularities in the surface the walking is better than in summer.

Above the limit of the trees the railway is covered with ice of every fantastic shape, and the framework of the Gulf tank is now so ornamented that one can hardly believe that it is the rude structure seen in summer. The Lizzie Bourne Monument, which one is accustomed to see only a rough pile of stones, is now an object of architectural beauty such as no sculptor can carve from marble. Immediately above the monument the timber trestles are completely covered with deposits of frozen mist extending two or three feet horizontally from the timber on which the track is laid, and every piece of timber which forms the trestle is ornamented with beautiful forms of frost-work, deposited in graceful curves as the wind sweeps through the trestle.

On the summit, the buildings, the piles of rock and stones, so rough in summer, are now completely covered with frost, while the snow fills the spaces between the jagged rocks. On the sides of the buildings towards the north-west the frost has accumulated, so that now it is more than a foot in thickness. The frost-work on the dépôt, while it has everywhere the same general appearance, the points show exactly the direction of the wind as it came into every nook and corner of the building. The frost on the braces and timbers that extend out ward seems like one triangular mass, and on the chains it is often two feet in diameter. The correspondent then adds :-

"Although I was on the mountain for ten days in October, yet I did not go to stay permanently until November 12 . It was expected that some of the party would be ready to go with me, but as they were not I went alone, and it was not till the last day of November that anyone came, so that I had the house and the mountain all to myself for nearly three weeks. During the greater part of November the weather was remarkably pleasant. On the 15 th, all day long, and far into the night, the clouds were below the summit of the mountain, and most of the time they covered the entire country. At times only the very highest point of Mount Washington was above the clouds. It reminded me forcibly of the time, during the Champlain period, when the whole of New England, except Mount Washington, was beneath the waves of the ocean. As 
the masses of clouds came over Adams and Jefferson, I looked until I almost persuaded myself that there were immense icebergs coming from the uplifted frozen North, but the illusion vanished as the summits appeared above the clouds. But what was remarkable is that the next day was pleasant.

"During the last two weeks in November, the average of the thermometer was $16^{\circ}$. The wind was north-west nearly the whole time. The weather was generally very mild, and the number of clear days was much greater than the average."

We may add to this interesting account that the daily telegrams received from the mountain have been full of interest. A temperature of $40^{\circ}$ below zero has not been uncommon, and we may well hope that the efforts of the solitary watchers on the inclement mountain-top will tend to advance the science of which they are such devoted students.

\section{SCIENCE IN VICTORIA}

T OSE who have read the Marquis de Beauvoir's "Voyage round the World" will recollect the high praise with which he speaks of Sir Redmond Barry's prolonged and continuous efforts for the advancement of science in Victoria. His latest good deed in this direction is the aid which he has afforded in the establishment of a School of Mines at Ballarat, which, to use his own words, may now be regarded as "an accomplished fact," since "everything connected with its establishment and maintenance has been thoroughly debated and determined on." The prospectus of the Institution states that "the object sought to be obtained is the combination of the highest scientific with the most practical training for all men engaged in the enterprise of mining in its various branches - whether so engaged as mining managers, engineers, surveyors, mechanists, working miners, directors or promoters of companies;" and, as there is every reason to believe that the school will be supported by the Government, by the several mining boards, and by the general public, we may hope to see it in actual operation in a few months.

We have not space to give a sketch of Sir Redmond Barry's excellent address, further than to remark that he points out the general bearings of chemistry, electricity, geology, steam, \&c., on the progress of mining; and we must content ourselves with the following extract relating to the progress of Science in Australia :-

"We are not," he observes, "even in our time, satisfied to import the discoveries of others, and to invite the man of science and the skilled artisan to direct their operations. Australia can point with a modest satisfaction to the invention of Osborne in photo-lithography, and the test for blood by Dr. Day ; ${ }^{*}$ to the cure for snake-bites by Professor Halford; to the method of removing pyrites, that inveterate enemy of the metallurgist, as well as the native alloys, from gold, and toughening the metal by the use of chlorine gas, by Mr. Miller of the Sydney Mint to the scientific preservation of the meat of our redundant flocks and herds, so largely exported; and also to many others, mention of which would delay us too long."

\section{THE CONTRACTION OF THE EARTH+}

THE phenomena, which were ably presented by the distinguished geologist, Mr. Lesley, to the National Academy of Sciences, and which seem to demonstrate that the outer shell * A full account of Dr. Day's remarkable colour-tests for blood and pus
may be found in Dr. Richardson's Report on Toxicology in the last number may be found in Dr. Richardson's Report

of the Mrom the Proceedings of the American Academy of Arts and Sciences, vol. viii. of the earth has sensibly shrunk, in some directions at least, since its original formation, naturally invite the attention of .phy. sicists to the possible causes of such a result. The most obvious cause of the shrinking of the earth is its cooling. But to shrink two per cent. linearly, which is the amount deduced by Mr.Lesley from the observed geological phenomena, involves a probable cooling of the whole earth of not less than two thousand degrees centigrade, which would require that its original temperature should be higher than would be consistent with the solidity of these shrunk strata.

Another source of change of form, which would produce shrinkages in different directions in different parts of the earth, is to be found in the diminution of oblateness arising from the diminished velocity of rotation upon the axis. Such diminution of the velocity of rotation has several years ago been shown by Mr. Ferrel to be caused by the action of the moon in producing the tides; this is, therefore, a true cause, and it is only necessary to examine how great its amount can be under any circumstances. This is all which is proposed in the present investigation, and the application to facts is reserved for geologists.

It is sufficient, for the present object, to regard the earth as homogeneous. Under this condition Laplace has shown that the time of the earth's rotation could not be less than about one-tenth of a day, which corresponds to a ratio of the axis of the equator to that of the pole, equal to 2.7197 , and an equatorial circumference 94 per cent. greater than the present one. Such is then the amount of shrinking which might have taken place, if any cause could be assigned capable of producing so great a reduction of the earth's velocity. The whole surface of the earth would have been about 130 per cent. larger than at present.

But the only cause at present known which would produce a sensible reduction of the earth's velocity is the lunar action upon the tides. But in this mutral action between the moon and the earth, the common rotation area of the earth and moon must remain unchanged. The question then arises, How great a reduction of the rotation area of the earth would have passed into that of the moon? In this inquiry it may be assumed that the moon revolves in a circular orbit in the plane of the earth's equator.

Now the moon's rotation area is 3.710 times the earth's. But if, in the origin, it had revolved just in contact with this earth, its rotation area would not have been less than 0.480 times the earth's, so that it could not have absorbed a rotation area from the earth greater than 3.236 times the earth's present rotation area, and therefore the earth's rotation area could never have exceeded 4.236 times that which it has at present. But, with the maximum velocity of rotation given by Laplace, the earth's rotation area would have been $37 \frac{1}{2}$ times greater than at present. It can never, therefore, have been reduced to so great an extent by the moon's action on the tides. But since, when the oblateness is small, the rotation area is nearly proportional to the velocity; and the excess of the square of the equatorial above that of the polar axis is nearly proportional to the square of the velocity, this excess may have been originally nearly eighteen times as great as at present, or about $15^{\frac{1}{2}}$ per cent. of the square of the polar axis. This would correspond to a figure of the earth in which the equatorial radius would have been about $2_{2}^{1}$ per cent. greater than at present ; so that it is sufficient to account for the observed phenomenon.

This peculiar form of shrinkage would produce the bighest mountains at the equator, and the tendency of the mountain ranges would then be to assume the direction of the meridian. But nearer the poles the mountains would be less elevated, and would rather tend towards the direction of the parallels of latitude.

It is, next, expedient to consider the mechanical question of the loss of living force in the case of the moon's action upon the waters of the earth, and its effect upon their different motions. In this connection there are problems worthy of the attention of geometers ; such as the relative motions of bodies rotating above the same vertical axis, towards which they are drawn by weights, and acting upon each other through the friction on the axis. For one of the bodies a rotating wheel may be substituted. There is also the case of two planets revolving about a primary, and acting upon each other through some form of friction.

In this way it will be seen that the planet or satellite once formed is constantly removed from the primary, and that planets tend to approach each other. It is interesting to consider whether this may not be one of the actual problems of nature.

B. PeIRCe 